\title{
Ecological Risk Assessment of Typical Plateau Lakes
}

\author{
Yuyadong ${ }^{1.2^{*}}$, Yankun $^{2}$ \\ ${ }^{1}$ School of Ecology and Environmental Science Yunnan University, China \\ 2.The Ecological and Environmental Monitoring Station of DEEY in Kunming, China
}

\begin{abstract}
Plateau lakes have significant ecological value. With economic development, lake pollution and ecological degradation have become increasingly prominent. There are many ecological risk assessment methods. This article combines four different ecological risk assessment methods including single-factor pollution index, geological accumulation index method, potential risk index method, and pollution load index method to analyze the heavy metal pollution in Yangzong seabed mud as comprehensively as possible. It shows that the results obtained by different ecological risk assessment methods are slightly different. The overall trends of the geological pollution index and the single-factor pollution index are similar. In terms of time, except for the two elements of mercury and cadmium, the contents of other heavy metals in 2019 are lower than in 2018, indicating that heavy metal pollution has decreased in 2019; from the perspective of spatial distribution, In 2018, the overall pollution level on the south side of Yangzonghai was higher than that in the central and northern regions of Yangzonghai . On the whole, whether it is the potential risk index or the appropriate pollution load index, the pollution level on the south side of Yangzonghai is higher than that in the central and northern areas of Yangzonghai, and the northern area has the least pollution.
\end{abstract}

\section{Introduction}

Lake is a water system except oceans, rivers and groundwater. Due to its own particularity and the dependence of urban development and economic and social development on lakes its status and role have become increasingly prominent. Since the mid-19th century, rapid economic development has caused 30-40\% of lakes and reservoirs to be polluted ${ }^{[1,2]}$. The heavy metal levels in many lakes near the industrial park and hometown were significantly higher than the background value. $\mathrm{Pb}, \mathrm{Cd}, \mathrm{Hg}, \mathrm{Zn}$ and $\mathrm{As}$ are especially derived from industrial emissions and other human activities. The ecological value of plateau lakes is significant, which plays an important supporting role in the economic and social development of the region and even the whole country. However, since the last century, lake pollution and ecological degradation have become increasingly prominent. Take the lakes on the Yunnan Plateau as an example.At present, the water quality of the heavily polluted Dianchi Lake, Silu Lake, and Yilong Lake is still in Class V or inferior to Class V, Xingyun Lake has been reduced from Class III to lower than Class V, and the water quality about arsenic pollution of Yangzonghai has been reduced to lower than Class V. Erhai Lake began to change from Type II to Type III seasonally, and Type II began to appear locally in Fuxian Lake. On the one hand, the development of economy and society has an increasing demand for water resources and ecosystems. On the other hand, the supply capacity of over-loaded and polluted ecosystems is relatively reduced, which makes the economic development of plateau lake basins face severe challenges.

The nine plateau lakes in Yunnan have four major functions as a whole (Yunnan Environmental Protection Bureau, June 2000): One is to support the development of metropolises; the second is to support the development of agriculture, especially modern agriculture; and the third is to support the development of tourism industry ; the fourth is to support the development of characteristic products. Those above four major functions play a pivotal strategic role of lake economic development in Yunnan Province. The plateau lakes of Yunnan are mostly distributed in Pingba District, which accounts for $6 \%$ of the province's land area. The lake district is the main grain producing area in Yunnan Province, bringing together $70 \%$ of the province's large and medium-sized enterprises.

Yangzonghai is a typical plateau lake. The terrain is generally high in the north and low in the south. It is surrounded by mountains, and the mountains are mostly north-south. The rivers are mostly north-south due to the influence of the topography, and are controlled by the north-south and east-west structures of basin and middlelow mountain hills. The basin belongs to the northern subtropical zone. ${ }^{[3]}$ 。Yangzonghai is an important water source in the area around the lake and downstream, and has the function of industrial and agricultural water, which plays an important role in regional economic development. [4] . In 2008, a serious arsenic pollution incident occurred in Yangzonghai, which reduced the environmental quality of Yangzong seawater. The content of arsenic in fish,

Corresponding author's e-mail: yuyadong@mail.ynu.edu.cn 
shrimp and other aquatic products was relatively high. Arsenic pollution in Yangzonghai has attracted widespread attention.. In terms of sediment heavy metals research, Zhang Yuxi et al. conducted research on the pollution characteristics, sources and potential ecological risks of heavy metals such as $\mathrm{As}, \mathrm{Cu}$, and $\mathrm{Cr}$ in sediments. However, the soil of Yunnan Province was used as the background in the study. Differences may affect the accuracy of the quantitative evaluation results of heavy metal pollution ${ }^{[5,6]}$.

\section{Methods}

\subsection{Study area}

Yangzonghai is a plateau faulted lake, located at $102^{\circ} 58^{\prime}-$ $103^{\circ} 01^{\prime}$ east longitude and $24^{\circ} 51^{\prime}-24^{\circ} 58^{\prime}$ north latitude. The lake shore is straight, the bottom of the lake is uneven, there are caves and reefs, the water color is green, the transparency is high, and it is a freshwater lake. It is one of the nine major lakes under protection in Yunnan Province, with an altitude of 1770 meters, a maximum water depth of 30 meters, a length of about 12 kilometers from north to south, and a width of about 3 kilometers from east to west. The lake water is recharged by surface runoff and lake precipitation, with a catchment area of $192.0 \mathrm{~km} 2$ and a recharge coefficient of 6.1 . The main rivers that enter the lake are Yangzong River, Qili River and temporary streams in the mountains on both sides of the east and west. ${ }^{[7]}$ 。

\subsection{Pre-treatment method}

Weigh $0.2 \mathrm{~g} \sim 0.3 \mathrm{~g}$ (accurate to $0.1 \mathrm{mg}$ ) sample (naturally air-dry to remove foreign matter such as plant roots and stones) in a 50m PTFE crucible or PTFE digestion tube, moisten with water and add $5 \mathrm{ml}$ hydrochloric acid. Heat at $100^{\circ} \mathrm{C}$ for $45 \mathrm{~min}$ on the graphite electrothermal digestion apparatus in a fume hood. Add $9 \mathrm{ml}$ of nitric acid and heat for $30 \mathrm{~min}$, add $5 \mathrm{ml}$ of hydrofluoric acid and heat for $30 \mathrm{~min}$, cool slightly, add $1 \mathrm{ml}$ of perchloric acid, cover and heat at $120^{\circ} \mathrm{C}$ for $3 \mathrm{~h}$; open the lid and heat at $150^{\circ} \mathrm{C}$ to emit white smoke, shake the digestion tube when heating. If there are black carbides on the inner wall of the digestion tube, add $0.5 \mathrm{ml}$ perchloric acid and continue heating until the black carbides disappear. Open the lid and heat at $160^{\circ} \mathrm{C}$ to drive the acid until the contents are in the form of non-flowing liquid beads (observe while it is hot). Add $3 \mathrm{ml}$ of nitric acid solution (1\%), warm to dissolve the soluble residue, transfer the entire amount to a $25 \mathrm{ml}$ volumetric flask, dilute to the mark with nitric acid solution (1\%), shake well, store in a polyethylene bottle, and let stand. Take the supernatant to be tested. Complete the analysis within 30 days.

\subsection{Measurement method}

In March 2018 and March 2019, samples were taken at the north, south, and center of Yangzonghai. Atomic fluorescence method is used for mercury and arsenic; graphite furnace atomic absorption method is used for cadmium; flame atomic absorption spectrophotometry is used for lead, copper, zinc, and chromium.

\subsection{Data analysis}

Use ARCGIS for mapping and spatial difference analysis, and use Excel and Origin for data calculation. Measure and calculate the heavy metal content in sediment samples, and use Hakason ecological risk index method, potential risk index method to calculate, process and analyze singlefactor pollution parameters, multi-factor pollution parameters and ecological risk parameters.

\subsection{Evaluation method of heavy metal pollution in sediments}

Yunnan Province is a well-known province with large mineral resources in the country, and the background value of soil elements is universally regionally high. ${ }^{[8]}$. Among the 160 kinds of useful mineral known in the world, 154 kinds have been discovered in Yunnan Province, accounting for $95.1 \%$ of the 162 kinds discovered in the country. There are 86 types of minerals with proven reserves, accounting for $53 \%$ of the country's 148 types, and 58 types of them are among the top 10 in the country, 25 types of them are even among the top 3 in the country, besides there're 6 types of minerals including lead, zinc, and germanium. The reserves rank is top one in the country. Except for the background values of chromium and mercury which are close to the national soil background values, the background values of other elements are higher than the national soil background values. Among them, cadmium, copper, nickel, and lead are significantly higher than the national soil, and the relative deviation is large; arsenic, fluorine and zinc are significantly higher than the national soil, and the relative deviation is small ${ }^{[9]}$ 。

\subsubsection{Single factor pollution index method}

The single factor pollution index first determines the evaluation standard, and selecting the correct evaluation standard is the key. Compare the actual value or true value of the evaluation standard with the evaluation standard. Determine the degree of pollution according to the ratio.

$$
P_{i}=C_{i} / C_{0}
$$

In the formula, $P_{i}$ is the pollution index, $C_{i}$ is the monitoring value, and $C_{0}$ is the evaluation standard.

Table 1 Soil background reference value and toxicity coefficient

\begin{tabular}{cccc}
\hline element & $\begin{array}{c}\text { Soil background } \\
\text { value in Yunnan } \\
\text { Province }\end{array}$ & $\begin{array}{c}\text { National } \\
\text { soil element } \\
\text { average }\end{array}$ & $\begin{array}{c}\text { Toxicity } \\
\text { factor } \\
\left(T_{r}^{i}\right)\end{array}$ \\
\hline $\mathrm{Cd}$ & 0.116 & 0.065 & 30 \\
$\mathrm{~Pb}$ & 37.93 & 26.50 & 5 \\
$\mathrm{Cu}$ & 33.97 & 22.60 & 5 \\
$\mathrm{Zn}$ & 77.70 & 74.4 & 1 \\
$\mathrm{Cr}$ & 68.14 & 61.1 & 2 \\
\hline
\end{tabular}




\begin{tabular}{llcl}
\hline $\mathrm{As}$ & 11.01 & 11.3 & 10 \\
$\mathrm{Hg}$ & 0.039 & 0.065 & 30 \\
\hline
\end{tabular}

\subsubsection{Geological Cumulative Index Method}

The geological cumulative index method can be used to evaluate the distribution of heavy metals in the environment under natural conditions or under the influence of man-made activities. The geological accumulation index method calculates the geological accumulation index value $I_{g e o}$ by measuring the concentration of environmental samples and the background concentration to evaluate the degree of environmental risk caused by a certain chemical ${ }^{[10,11]}$.

$$
I_{\text {geo }}=\log 2\left[\frac{C_{n}}{k \times B E_{n}}\right]
$$

In the formula, $I_{g e o}$ is the geological accumulation index, $C_{n}$ is the concentration of element $\mathrm{n}$ in the sample, $B E_{n}$ is the environmental background concentration, and $\mathrm{K}$ is the modified index, which is usually used to characterize sedimentary characteristics and other effects.

Table 2 Pollution Grading Table

\begin{tabular}{|c|c|c|c|}
\hline$I_{g e o}$ & $\begin{array}{c}\text { Pollution } \\
\text { degree }\end{array}$ & $I_{g e o}$ & Pollution degree \\
\hline$I_{g e o} \leq 0$ & No pollution & $\begin{array}{c}3< \\
I_{g e o} \leq 4\end{array}$ & $\begin{array}{l}\text { Serious } \\
\text { pollution }\end{array}$ \\
\hline $0<I_{g e o} \leq 1$ & $\begin{array}{l}\text { Light } \\
\text { pollution }\end{array}$ & $\begin{array}{c}4< \\
I_{g e o} \leq 5\end{array}$ & $\begin{array}{c}\text { Serious- } \\
\text { extremely } \\
\text { serious pollution }\end{array}$ \\
\hline $1<I_{g e o} \leq 2$ & $\begin{array}{l}\text { Moderately } \\
\text { polluted }\end{array}$ & $I_{g e o}>5$ & $\begin{array}{l}\text { Extremely } \\
\text { serious pollution }\end{array}$ \\
\hline $2<I_{g e o} \leq 3$ & $\begin{array}{l}\text { Moderate- } \\
\text { severe } \\
\text { pollution }\end{array}$ & & \\
\hline
\end{tabular}

\subsubsection{Potential ecological risk index method}

The potential ecological risk index method is a sedimentological method to calculate the main pollutants such as heavy metals in water bodies. By calculating the potential ecological risk factor Eir and the potential ecological risk index, RI can evaluate the pollution degree of heavy metals in water body sediments ${ }^{[12]}$ :

$$
C_{f}^{i}=\frac{C_{D}^{i}}{C_{R}^{i}}, \quad C_{D}=\sum_{i=1}^{m} C_{f}^{i}, E_{r}^{i}=T_{r}^{i} \times C_{f}^{i}, R I=\sum_{i=1}^{m} E_{r}^{i}
$$

In the formula, $C_{f}^{i}$ is the pollution coefficient of metal $\mathrm{i}, C_{D}^{i}$ is the actual concentration value of metal $\mathrm{i}, C_{R}^{i}$ is the highest background value of the $\mathrm{i}$-th heavy metal in sediments before modern industrialization, $C_{D}$ is the degree of multiple metal pollution, $T_{r}^{i}$ is the biological toxicity coefficient of heavy metals, $E_{r}^{i}$ is the potential ecological risk factor of metal $i$, and RI is the potential ecological risk index of polymetallic.
Table 3 The degree of heavy metal pollution in sediments and the classification standard of potential risk index

\begin{tabular}{cccc}
\hline $\begin{array}{c}\text { Ecological } \\
\text { Risk Index }\end{array}$ & $E_{r}^{i}$ & $\begin{array}{c}\text { Total } \\
\text { ecological } \\
\text { risk level }\end{array}$ & RI \\
\hline Light & $<40$ & Light & $<150$ \\
Medium & {$[40,80)$} & Medium & {$[150,300)$} \\
Strong & {$[80,160)$} & Strong & {$[300,600)$} \\
Very Strong & {$[160,320)$} & $\begin{array}{c}\text { Extremely } \\
\text { Strong }\end{array}$ & $\geq 600$ \\
Extremely & $\geq 320$ & & \\
Strong & & & \\
\hline
\end{tabular}

\subsubsection{Pollution Load Index Method}

The pollution load index method was proposed by British scientist Tomlinson et al. in 1980. This method can quantitatively evaluate various heavy metals at various points in the entire region and classify the pollution degree of each point. It can intuitively reflect the pollution caused by various heavy metals. ${ }^{[13]}$ :

$$
F_{i}=C_{i} / C_{0}
$$

In the formula, $F_{i}$ is the highest pollution coefficient of element i, $C_{i}$ is the measured content of element i, and $C_{0}$ is the evaluation standard of element $i$.

The pollution load index at a certain point is:

$$
I_{P L}=\sqrt[n]{F_{1} \times F_{2} \times F_{3} \times \ldots \times F_{n}}
$$

In the formula: $I_{P L}$ is the pollution load index at a certain point; $\mathrm{n}$ is the number of evaluation elements. The pollution load index is generally divided into 4 levels.

Table 4 The relationship between pollution load index and pollution degree

\begin{tabular}{ccc}
\hline pollution index & Grade & Pollution degree \\
\hline$I_{P L}<1$ & 0 & No pollution \\
$1 \leq I_{P L}<2$ & 1 & Moderately \\
& & polluted \\
$2 \leq I_{P L}<3$ & 2 & Strong pollution \\
$I_{P L} \geq 3$ & 3 & Extreme pollution \\
\hline
\end{tabular}

\section{3 result}

\subsection{Single factor pollution index method}

Through the analysis of the single factor pollution index of heavy metals in the north, center, and south of Yangzonghai in 2019 and 2018, it can be found that the heavy metal mercury pollution on the north side of Yangzonghai and the center of Yangzonghai has nearly doubled; for Yangzonghai heavy metals ,the migration of lead and heavy metal zinc does not change with time and place; the pollution of heavy metal copper and heavy metal arsenic has improved in 2019 compared with 2018; the change of heavy metal cadmium is unstable. In general, the pollution of cadmium in 2019 is more serious. The cadmium in Zonghai Center increased from 1 to 13, and it increased in 2019 on the north and south side of 
Yangzonghai compared with 2018; the pollution of heavy metal chromium has improved in 2019. Overall, the heavy metal pollution in the southern part of Yangzonghai is slightly higher than that in the northern part.

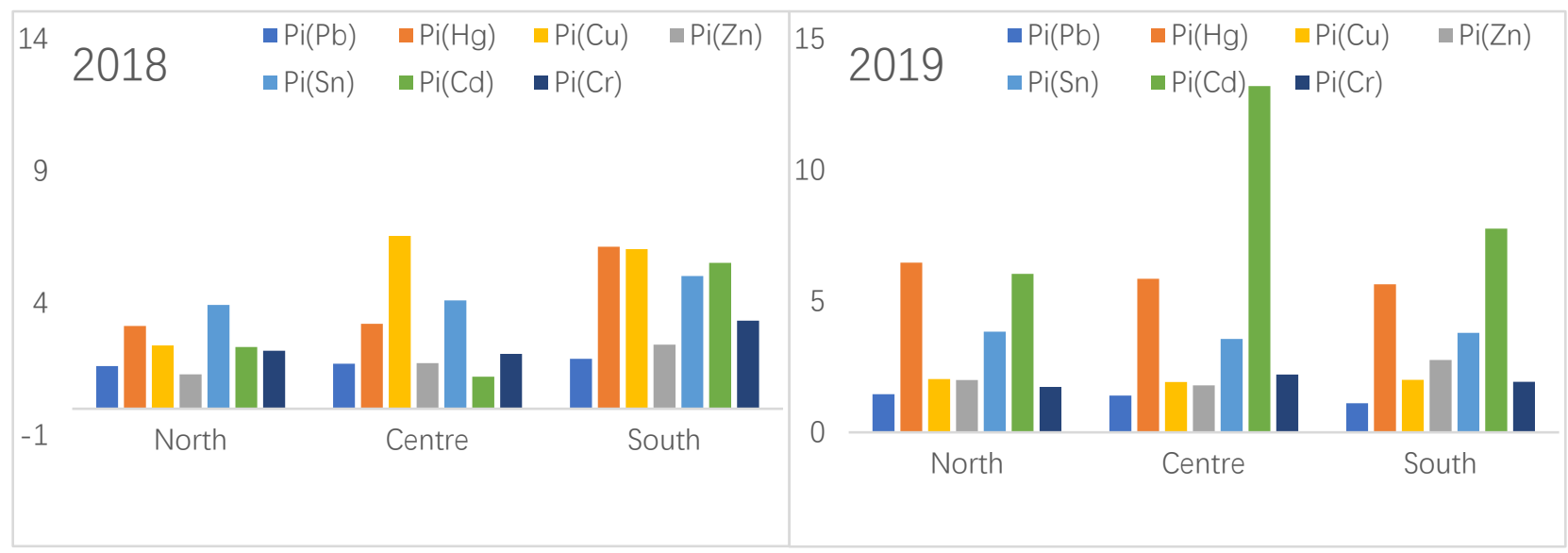

Figure 1 Heavy metal single factor pollution index

\subsection{Geological Cumulative Index Method}

The overall trends of the geological pollution index and the single-factor pollution index are similar. It can be seen from the time that the content of other heavy metals in 2019 is lower than 2018, except for the two elements of mercury and cadmium, indicating that heavy metal pollution has decreased in 2019; from the perspective of spatial distribution In 2018, the overall pollution level on the south side of Yangzonghai was higher than that in the central area and the northern part of Yangzonghai, which was consistent with Zhang Yuxi's 2012 data analysis results. ${ }^{[5]}$. It is worth noting that heavy metal mercury pollution. After the Yangzonghai pollution incident broke out in 2008, the valence analysis and emission control of mercury elements are the focus of people's concerns. The data shows that the contents and risks of heavy metal mercury from-Yangzonghai inspection in 2019 are significantly higher, not to mention the central area of Shiyangzonghai which needs to be paid more attention to.

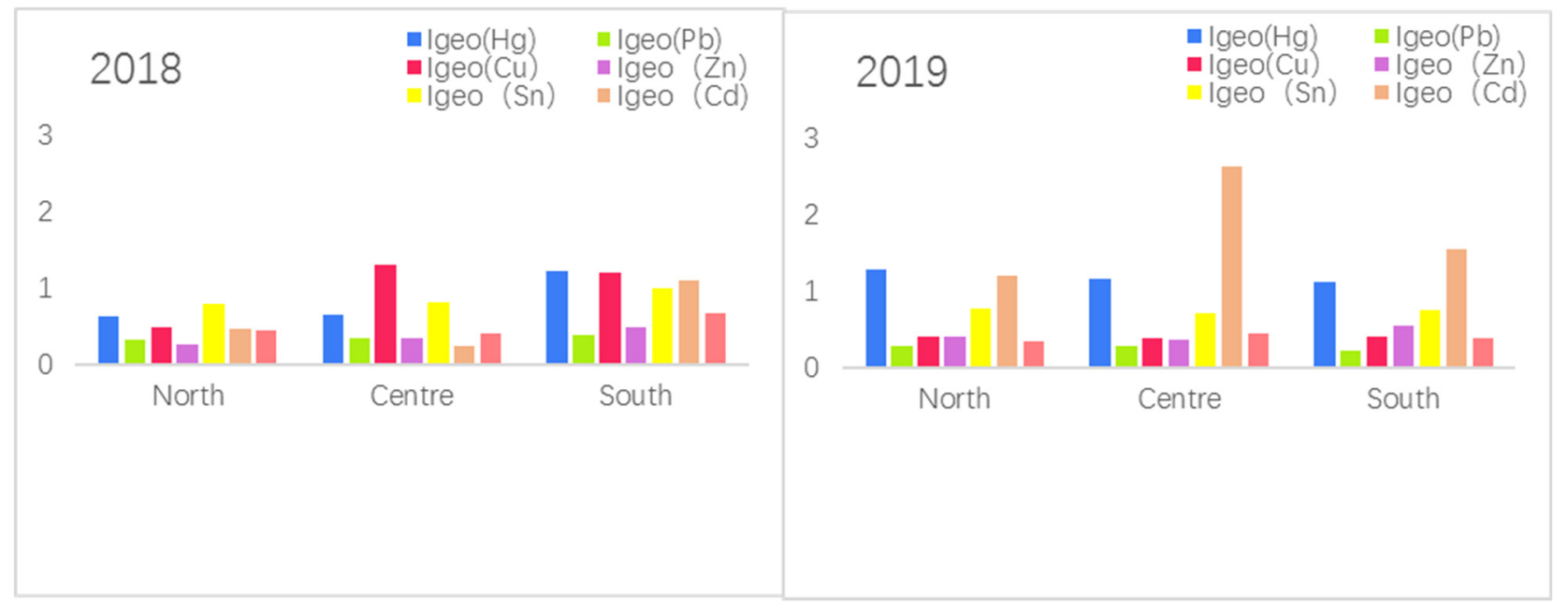

Figure 2 Geological Cumulative Index Method 


\subsection{Potential ecological risk index method and pollution load index method}

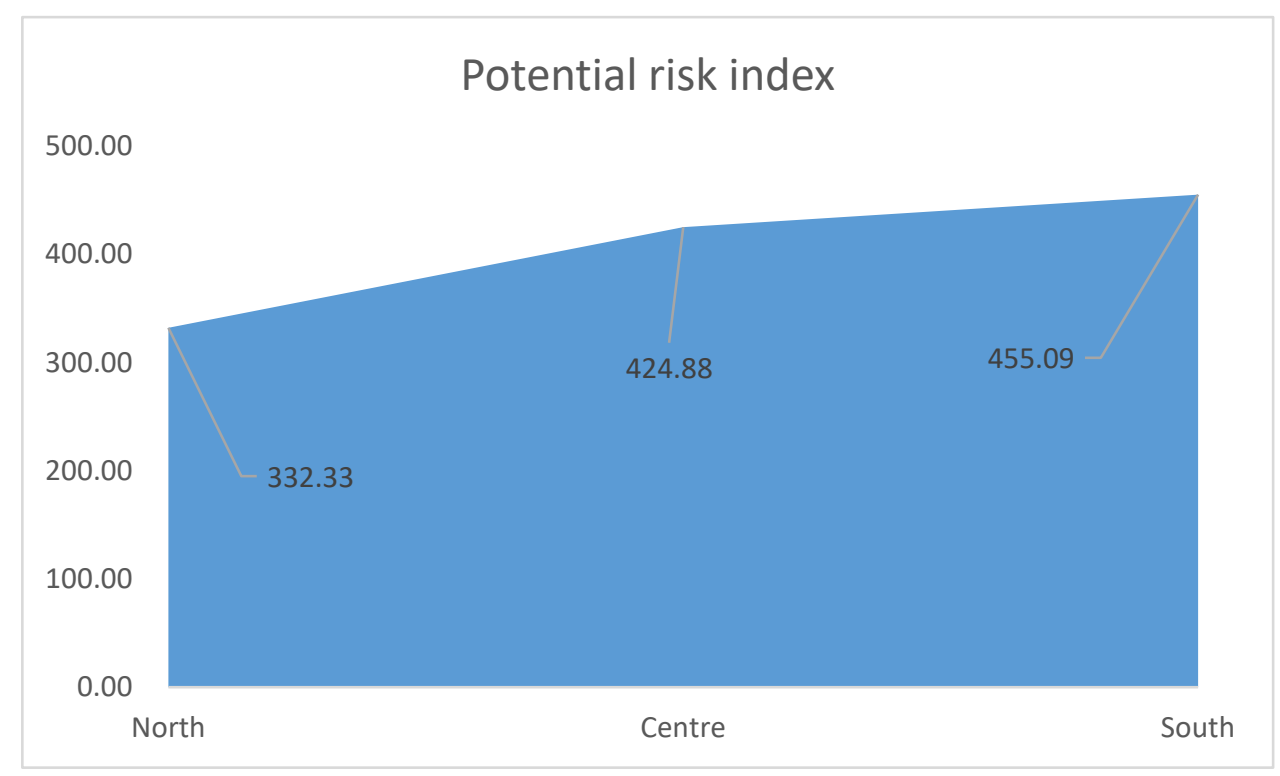

Figure 3 Average value of Yang Zonghai's two-year potential risk index

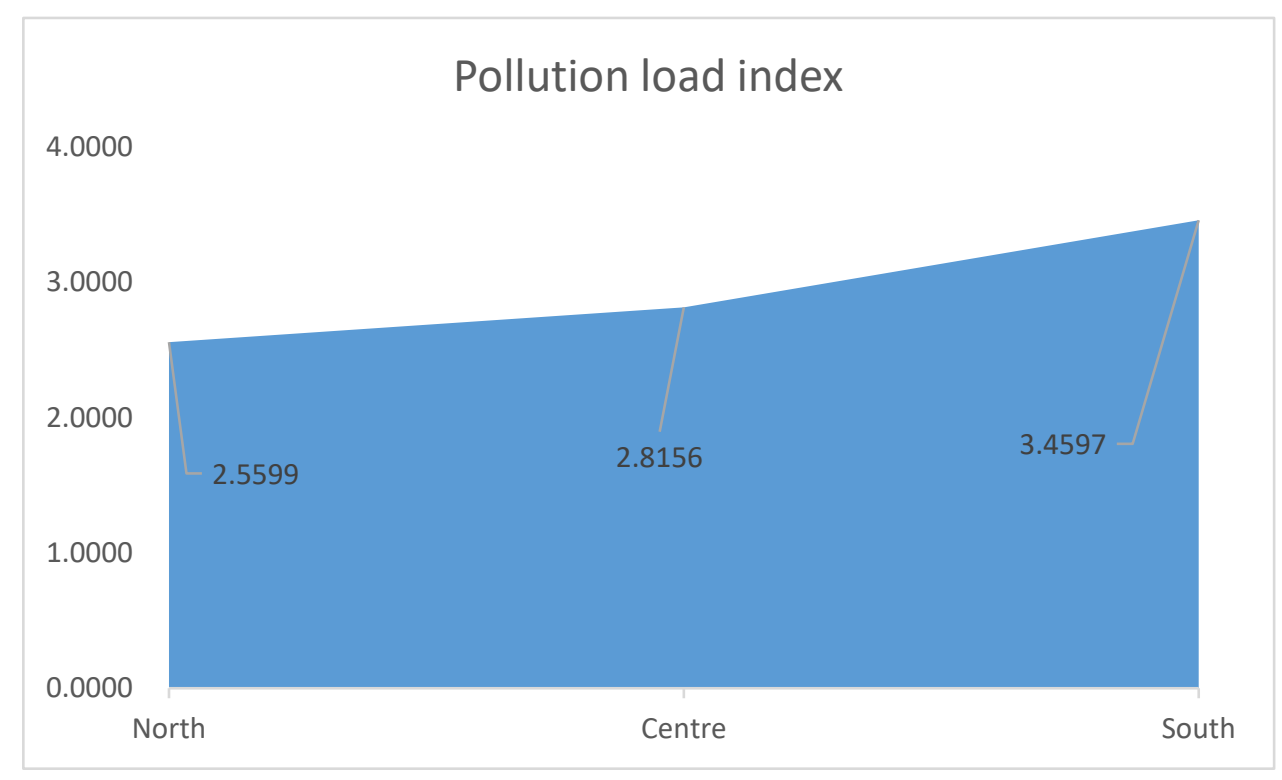

Figure 4 Average value of pollution load index of Yangzonghai in 2 years

The potential risks of the sampling points on the north, center, and south sides of Yangzonghai are all severely polluted. Among them, the sampling risk on the north side of Yangzonghai is the lowest at 332.32, and the sampling point on the south side has the highest pollution at 455.09. The values of three sampling points produced by the pollution load index method are all classified as severe pollution. On the whole, whether it is the potential risk index or the appropriate pollution load index, the pollution level on the south side of Yangzonghai is higher than that in the central and northern areas of Yangzonghai, and the northern area has the least pollution.

\section{Discussion}

Zhang Yuxi analyzed heavy metals in Yangzonghai sediments in 2012 and found that the horizontal distribution characteristics of heavy metals in Yangzonghai surface sediments can be roughly divided into two types. The distribution characteristics of $\mathrm{Zn}, \mathrm{Cr}$, $\mathrm{Pb}$, and $\mathrm{As}$ are similar. The mass ratio on the north and south coasts of Yangzonghai is relatively high, while the quality in the middle area of Yangzonghai is relatively low. The highest value of mass ratio is in Tangeying on the south bank of Yangzonghai. Nearby, the second highest value is near Shijiazui on the north bank of Yangzonghai. The distribution characteristics of $\mathrm{Ti}, \mathrm{Mn}, \mathrm{V}, \mathrm{Cu}, \mathrm{Ni}$, and Co are similar, and their high mass ratio points are all located near Huangshui Cave on the east bank of Yangzonghai, while the mass ratio of heavy metals on the north and south banks of Yangzonghai is relatively low. ${ }^{[5]}$. This point is roughly similar to the results of this article. 
According to the data analysis results in 2018 and 2019, it can be seen that the content of zinc $(\mathrm{Zn})$ in the south is higher than that in the central and northern parts, but the distribution trend of chromium content in 2018 is the north and south which is higher than the one from central part . But in 2019, the total chromium content of the north and south sides has been greatly reduced based on the measures taken in 2019. The distribution of lead and arsenic did not change significantly.

Duan Zhibin collected data on the average content of 8 heavy metals in Caohai, Waihai, Yangzonghai and Dianchi Lake, Yunnan Province in $2017^{\text {[14]: }}$

Table 5 Heavy metal content in typical plateau lakes

\begin{tabular}{cccccccccc}
\hline area & lake & $\mathrm{Zn}$ & $\mathrm{Cu}$ & $\mathrm{Pb}$ & $\mathrm{Cr}$ & $\mathrm{Cd}$ & $\mathrm{Hg}$ & $\mathrm{As}$ & $\mathrm{Ni}$ \\
\hline Yunnan & Dianchi & 1112 & 796 & 363.4 & 91 & 64.76 & 1.10 & 146.4 & \\
& $\begin{array}{c}\text { Caohai } \\
\text { Dianchi Lake }\end{array}$ & 255 & 197 & 88.0 & 63 & 0.3 & 0.21 & 48.15 & \\
& Yang Zonghai & 149.2 & 97.6 & 40.3 & 145.8 & & & 10.8 & 55.1 \\
\hline
\end{tabular}

Comparing the heavy metal content of Yang Zonghai in 2017 with the sampling analysis in 2019 in the above table, it can be seen that the pollution of heavy metal copper has dropped from 97.6 in 2017 to 67.33 in 2019; but the content of heavy metal arsenic has increased from 10.8 in 2017 to 41 . In 2019, it can be seen that the pollution of heavy metal arsenic has increased, and attention should be paid in time.

There are two main sources of heavy metals in the sediments, one is human activity factors such as pollution from industry, mining, and tourism, and the other is geochemical processes such as rock weathering. The two sources are the main reasons for the two different characteristics of the level distribution of heavy metals in the sediments. Affected by human activities such as pollution from industry, mining and tourism. Zn mainly comes from industries containing arsenic ores. For example, the main raw material of the Yangzonghai Nanan Phosphate Fertilizer Plant is sulfide-zinc ore, and the mass ratio of $\mathrm{Zn}$ in the nearby sediments is generally higher. $\mathrm{Cr}$ mainly comes from sewage discharged from the processing of chromium-containing ore and metal surface treatment. $\mathrm{Pb}$ mainly comes from coal-burning by enterprises on both sides of the strait. For example, the mass ratio of $\mathrm{Pb}$ in the sediments near the thermal power plant on the north bank of Yangzonghai is relatively high. As mainly comes from the utilization of arseniccontaining ores. The hot spring water, lignite, and sulphurzinc mines in the Yangzonghai area contain high levels of arsenic. Therefore, the mass ratio of As in the sediments near the hot springs, thermal power plants, coal mines and the phosphate fertilizer plant on the north bank of Yangzonghai is relatively high ${ }^{[5]}$, This is similar to the source of Erhai sediments ${ }^{[15]}$, The anthropogenic emissions of $\mathrm{Cd}, \mathrm{Pb}$, and $\mathrm{Zn}$ in Erhai Lake sediments mainly come from atmospheric sources emitted by mining and smelting ${ }^{[16,17]}$ 。 Since there are no companies involved in heavy metal copper $(\mathrm{Cu})$ in the Yangzonghai area, the distribution characteristics have nothing to do with the areas where human activities are intensive. It is speculated that it is produced by geochemical processes such as rock weathering. $\mathrm{Cr}$ and $\mathrm{Hg}$ pollution may be related to the surrounding chemical industry.

Each method of ecological risk assessment has applicability and limitations. Usually, when doing ecological risk assessment, two or three different ecological risk assessment methods are combined for comprehensive comparison. The address accumulation index method and the potential risk index method are combined to analyze the surface sediments of Daming Lake ${ }^{[18]}$, the sediments of the Dongting Lake basin ${ }^{[19]}$, and the Caohai sediments of Guizhou [20], the surface layer of shallow lakes in Jiangsu Province ${ }^{[21,22]}$, major lakes in Nanjing ${ }^{[23]}$, lakes along the Yangtze River in Anqing, and sediments of the Yangtze River Pollution characteristics of heavy metals in materials [24]; Nemeiro comprehensive pollution index combined with the potential risk index method to analyze the pollution characteristics in the bottom mud of the Zhongba River in Beijing (Yang Lanqin 2021); the middle and lower reaches of the Yangtze River The lakes mainly adopt the potential ecological risk assessment method (Bing Haijian 2010, Yang Hui 2013). This paper combines four different ecological risk assessment methods: single factor pollution index, geological cumulative index method, potential risk index method, and pollution load index method to analyze the pollution status of heavy metals in Yangzong seabed mud more comprehensively. The results of ecological risk analysis and ecological risk analysis show that economic development, land use types, soil parent materials, rainfall and snowmelt have a greater impact on the accumulation of heavy metals in lake sediments. The research results can provide reference for the treatment of residual lake pollution in Northwest China and globally ${ }^{[25]}$.

\section{Conclusion}

In terms of time, the heavy metal pollution in Yangzonghai has improved slightly (except for mercury pollution); in terms of distribution, the pollution in the central and southern parts of Yangzonghai is slightly more serious than that in the northern part; different ecological risk assessment methods apply to the same area. The analysis is slightly different. Choosing an appropriate evaluation method plays a key role in accurate ecological analysis and risk prediction. Combining multiple evaluation methods can better and more comprehensively analyze the pollution status and risk estimation of lakes in order to adopt corresponding management methods. Unreasonable production methods and lifestyles are the key to the problem. For a long time, we have adopted an extensive growth mode that prioritizes the development of heavy 
industry, high accumulation, and high speed. This is very necessary to change the backward view of manufacturing, enhance national strength, and improve people's living standards. However, due to this traditional method, the investment is large, the output is small, the economic benefit is low, the waste of resources is serious, and the damage to the ecological environment is serious. At the same time, population growth is also the more prominent situation of water resources, such as lake enclosure, agricultural irrigation, domestic water used by industrial and domestic wastewater, which put human society in danger. In addition, the increments of population will inevitably lead to the over-exploitation and consumption of other natural resources that will aggravate environmental pollution and resource extinction. Combining human factors and natural pollution sources, the development and treatment of Yangzonghai Lake should focus on following ecological treatment methods to restore the ecological functions of Yangzonghai Basin.

\section{Acknowledgments}

Authors wishing to acknowledge assistance or encouragement from colleagues, special work by technical staff or financial support the paper. Thank the reviewers for their patience and guidance, and thank all the staff.

\section{References}

1. Yu, W., J. Wang, and S. Zang, The Spatial Variability Characteristics and Potential Ecological Risk Assessment of Heavy Metals of Lake Sediments in the Songnen Plain. Scientia Geographica Sinica, 2012. 32(8): p. 1000-1005.

2. Mamat, Z., et al., An ecological risk assessment of heavy metal contamination in the surface sediments of Bosten Lake, northwest China. Environ Sci Pollut Res Int, 2016. 23(8): p. 7255-65.

3. Li, Z., et al., Speciation and Distribution of Arsenic and Its Stability Assessment in Lake Yangzonghai Sediments after Arsenic Pollution Remediation. Enuivonmental Science and Technology, 2015.38(2): p. 41-47.

4. ZhenHua, W., et al., The levels,trends and risk assessment of arsenic pollution in Yangzonghai Lake, Yunnan. Scientia Sinica Chimica, 2011. 41(3): p. 556-564.

5. Zhang, Y.-X., et al., Distribution and sources of arsenic in Yangzonghai Lake, China. Huan jing ke $\mathrm{xue}=$ Huanjing kexue, 2012. 33(11): p. 3768-77.

6. N'Guessan, Y.M., et al., Trace elements in stream bed sediments from agricultural catchments (Gascogne region, S-W France): Where do they come from? Science of the Total Environment, 2009. 407(8): p. 2939-2952.

7. Yuan, L., et al., Effect of daily thermal stratification on dissolved oxygen, $\mathrm{pH}$, total phosphorus concentration, phytoplankton and algae density of a deep plateau lake: A case study of Lake Yangzonghai,
Yunnan Province. Journal of Lake Sciences, 2014. 26(1): p. 161-168.

8. Yongfeng, W.U., L.I.U. Congqiang, and T.U. Chenglong, SPECIATION OF HEAVY METALS IN URBAN SOIL AT GUIYANG. Acta Mineralogica Sinica, 2008. 28(2): p. 177-180.

9. Xiaolin, Z., et al., Dynamic monitoring and the results analysis of the environmental quality on three basic farmland in Yunnan. Southest Chnia Journal of Agricultural Sciences, 2006. 19(4): p. 616-620.

10. Jing, P., L.I. Zeqin, and H.O.U. Jiayu, Application of the Index of Geo-accumulation Index and Ecological Risk Index to Assess Heavy Metal Pollution in Soils. Guangdong Trace Elements Science, 2007. 14(8): p. 13-17.

11. Zhang, S. and H. Liu, Review of ecological risk assessment methods. Acta Ecologica Sinica, 2010. 30(10): p. 2735-2744.

12. HAKANSON, L., $<A N$ ECOLOGICAL RISK INDEX FOR AQUATIC POLLUTION CONTROL A SEDIMENTOLOGICAL APPROACH.pdf $>1980$.

13. Gao, J. and J. Wang, TWO ASSESSMENT METHODS OF HEAVY METAL POLLUTION OF RIVER SEDIMENT ECOLOGICAL RISK. Environment Engineering, 2013. 31(2): p. 119-121.

14. Duan Zhibin, Cai Xiongfei, Wang Ji, anjiping. Evaluation of heavy metal pollution in sediments of plateau lakes in China [J]. Environmental science and technology,,2017,40(S1):293-298.

15. Yu, Z., et al., Comprehensive assessment of heavy metal pollution and ecological risk in lake sediment by combining total concentration and chemical partitioning. Environ Pollut, 2021. 269: p. 116212.

16. Li, K., et al., Historical variations of atmospheric trace metal pollution in Southwest China: Reconstruction from a 150-year lacustrine sediment record in the Erhai Lake. Journal of Geochemical Exploration, 2017. 172: p. 62-70.

17. Lin, Q., et al., Spatial distribution, contamination and ecological risk assessment of heavy metals in surface sediments of Erhai Lake, a large eutrophic plateau lake in southwest China. Catena, 2016. 145: p. 193203.

18. Dai, J., et al., Pollution characteristics and ecological risk assessment of heavy metals in the surface sediments of Daming Lake. Environmental Chemistry, 2020. 39(1): p. 249-263.

19. Li, Z., et al., Distribution and Ecological Risk Assessment of Nitrogen,Phosphorus and Heavy Metals in Surface Sediments of Typical Internal Lakes in Dongting Lake Area. Research of Environmental Sciences, 2020. 33(6): p. 1409-1420.

20. Song, Y., et al., Spatiotemporal distribution and potential ecological risk assessment of heavy metals in the sediments of Lake Caohai,Guizhou,China. Chinese Journal of Ecology, 2016. 35(7): p. 18491856.

21. Jiang, Y., et al., POLLUTION CHARACTERISTICS 
AND POTENTIAL ECOLOGICAL RISK ASSESSMENT OF HEAVY METALS IN SURFACE SEDIMENTS OF SHALLOW LAKES IN JIANGSU PROVINCE,CHINA. Resources and Environment in the Yangtze Basin, 2015. 24(7): p. 1157-1162.

22. Chen, Q., et al., Distribution and Ecological Risk Assessment of Heavy Metals in Surface Sediments from the Lakes of West Jiangsu Province. Journal of Agro-Environment Science, 2013. 32(5): p. 10441050.

23. Ma, T., et al., Potential Ecological Risk Assessment of Heavy Metal Pollutants in Surface Sediments of the Lakes in Nanjing. Journal of Ecology and Rural Environment, 2011. 27(6): p. 37-42.

24. Li, F., et al., Pollution characteristics and ecological risk assessment of heavy metals in the sediments from lakes of Anqing City and Anqing section of Yangtze River. Journal of Agro-Environment Science, 2017. 36(3): p. 574-582.

25. Zulpiya-Mamat, et al., Changes of the Ecosystem Service Values of the Wetlands of Small Lake in Bosten Lake Basin During the Period from 1976 to 2011. Research of Soil and Water Conservation, 2016. 23(3): p. 328-332,337. 